\title{
Scrotal Lymphedema and its Conservative Treatment: A Rare Complication of Circumcision
}

\author{
Serkan Akan1, Berna Urkmez², Ilker Artuk³ and Ahmet Urkmez³ \\ 1Department of Urology, University of Health Sciences, Sultan Abdulhamid Han Research and Training Hospital, Istanbul, Turkey \\ ${ }^{2}$ Department of Physical Medicine and Rehabilitation, Bezmialem University Faculty of Medicine, Istanbul, Turkey \\ ${ }^{3}$ Department of Urology, University of Health Sciences, Haydarpasa Numune Research and Training Hospital, Istanbul, Turkey
}

\begin{abstract}
Lymphedema is defined as an abnormal accumulation of extracellular fluid in the subcutaneous compartment caused by impaired lymphatic drainage. Scrotal lymphedema is a rare condition characterised by swelling of the scrotal skin due to deterioration in lymphatic drainage. Over time, fibrosis may develop in the scrotum and genital malformations that impair the patient's quality of life. Here, we present the first case in our experience of scrotal lymphedema, which occurred in a 3-year child following circumcision, and subsequently was treated successfully with complex decongestive physiotherapy.
\end{abstract}

Key Words: Circumcision, Complex decongestive physiotherapy, Lymphedema, Scrotum.

How to cite this article: Akan S, Urkmez B, Artuk I, Urkmez A. Scrotal lymphedema and its conservative treatment: A rare complication of circumcision. J Coll Physicians Surg Pak 2020; 30(1):94-95.

\section{INTRODUCTION}

Scrotal lymphedema is a rare condition characterised by swelling of the scrotal skin due to deterioration in lymphatic drainage. Primary scrotal lymphedema is usually congenital, while secondary lymphedema is mostly due to filariasis in tropical countries. ${ }^{1}$ Circumcision may also be counted as a secondary cause. Here, the anatomical relationship between the superficial inguinal lymph nodes and superficial lymphatic system of the penis is in the foreground. ${ }^{2}$

Scrotal lymphedema is characterised clinically by edema and painless enlargement of the scrotum. Fibrosis may develop in the scrotum, leading to genital malformations that impair the patient's quality of life. ${ }^{3}$ Treatment is mostly conservative, but it is difficult to apply these methods to the genital area.

Herein, we present, as far as we know, a first case of scrotal lymphedema, which occurred following circumcision in a 3-year-old child and was treated with complex decongestive physiotherapy (CDT).

\section{CASE REPORT}

A 3-year male child was brought to our clinic with the request for circumcision for religious / cultural reasons. On physical examination, the development of external genitalia was normal and there was no previous illness

Correspondence to: Dr. Ahmet Urkmez, Department of Urology, University of Health Sciences, Haydarpasa Numune Research and Training Hospital, Tr-34668 Istanbul, Turkey

E-mail: ahmeturkmez@hotmail.com

Received: June 04, 2018; Revised: April 02, 2019;

Accepted: April 20, 2019 and surgery. The socio-cultural level and hygiene conditions of the child and his family were good. The patient was circumcised with dorsal slit method, followed by administration of prophylactic antibiotic and antiinflammatory treatment (cefuroxime 125mg / $5 \mathrm{ml}+$ ibuprofen $100 \mathrm{mg} / 5 \mathrm{ml}$ ). On the third postoperative day, the patient presented to our center with complaints of enlargement of the scrotum (Figure 1). Physical examination and scrotal ultrasonography (USG) were evaluated and diagnosed as scrotal lymphedema. Antibiotic and anti-inflammatory treatment was continued for 7 days. Observing no reduction in lymphatic edema, we consulted the Physical Therapy and Rehabilitation Clinic. In this clinic, CDT was applied and, after 10 days of treatment, lymphatic edema was completely reduced.

\section{DISCUSSION}

Male circumcision is one of the oldest and most commonly performed surgeries in history. While no complication is observed in most patients, rarely complications may occur, including excessive or inadequate skin removal, pain, hemorrhage, infection, skin bridge, meatal stenosis, meatal ulcers, loss of penile sensitivity, urethro-cutaneous fistula, sexual dysfunction and penile amputation. ${ }^{1}$

Lymphedema is defined as an abnormal accumulation of extracellular fluid in the subcutaneous compartment due to impaired lymphatic drainage. ${ }^{2}$ Inhibition of lymphatic flow leads to ductal dilatation, accompanied by hypertrophy and interstitial edema. ${ }^{3}$ Primary lymphedema originates from intrinsic impairment of lymphatic vessels and about $14 \%$ is inherited. ${ }^{4}$ Primary lymphedema is classified as either age-related congenital lymphedema or late-onset lymphedema, which can be seen after 35 years of age. 


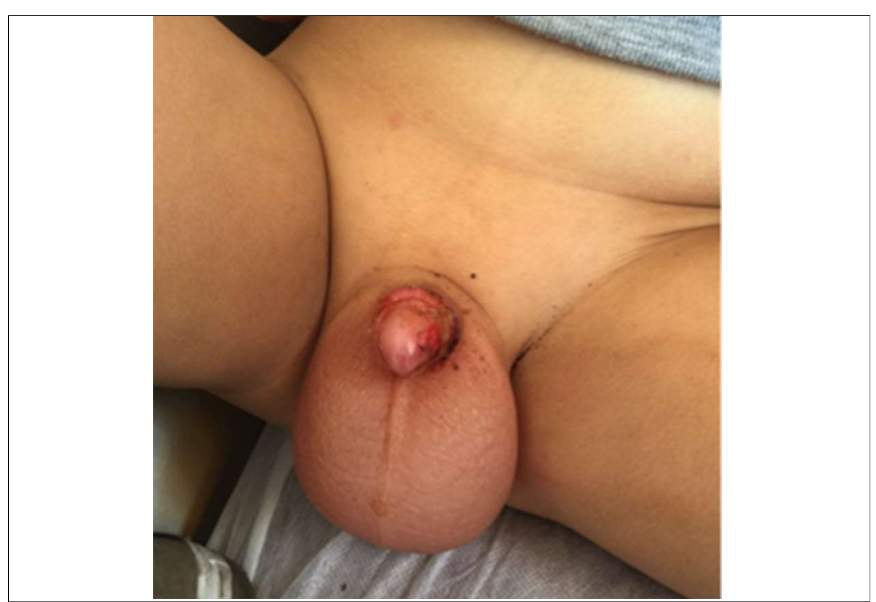

Figure 1: Scrotal lymphedema, which occurred after circumcision in a 3-year child.

Secondary lymphedema is most often caused by tropical country roundworm Wuchereria Bancrofti, or due to surgery, infections and radiotherapy. ${ }^{5}$ The underlying pathophysiology is that the lymphatic drainage is interrupted due to damage or surgical removal of lymphatic vessels.

In males, genital lymphedema may affect the penis and scrotum in isolation, but may also coexist in all external genitalia. The penis has two lymphatic systems: superficial and deep. The superficial system empties the superficial inguinal lymph nodes of the preputium, penis skin, and scrotal skin; while in the deep system, glans is drained directly into the pelvic lymph nodes. 6 Therefore, as the excision of the preputium reaches the superficial lymph nodes, the scrotal skin will be affected; while the glans will be completely normal, as in our patient.

Scrotal lymphedema is clinically characterised by edema and painless enlargement of the scrotum. Over time, fibrosis may develop in the scrotum and genital malformations impairing quality of life. ${ }^{7}$ Scrotal lymphadenopathy is clinically diagnosed, but scrotal USG and magnetic resonance imaging (MRI) can exclude other possible etiologies. ${ }^{8}$ Patients with mild symptoms can be treated with local hygiene, compression, elevation of the affected limbs, diuretics and benzopyrones. Such interventions decrease the amount of protein in the interstitial tissue, activate macrophages, enhance the capillary barrier to prevent exudation of proteins, lower hydrostatic pressure and lower the risk of infection. 9 In severe cases, tissue resection, skin grafts and vascular reconstruction may be needed. ${ }^{10}$

Because of anatomical features, the application of conservative methods to the genital region is difficult. However, if performed by experienced therapists, it can lead to a significant decrease in genital volume. Components of CDT are as follows: manual lymphatic drainage, compression therapy, decongestive kinesi-therapy, and good skin care, which increase the transport capacity of the lymphatic vessel system. CDT is accepted as the main conservative treatment method for primary and secondary lymphedema, lipolymphedema, and phlebolymphedema. ${ }^{9,10}$ Additionally, CDT may facilitate genital reduction by providing decrease of pre-operative edema in severe lymphocytic patients. ${ }^{9}$ Despite post-surgery antibiotic and anti-inflammatory prophylaxis, a conservative approach was preferred for the patient with scrotal lymphedema and permanent treatment with CDT was provided in our case. We should also keep in mind that although post-circumcision lymphedema is very rare, CDT is an effective conservative treatment option that can be applied.

\section{CONFLICT OF INTEREST:}

Authors declared no conflict of interest.

\section{AUTHORS' CONTRIBUTION:}

SA: Design and writing of manuscript.

$\mathrm{BU}$ : Design of mauscript; and literature review.

IA: Data collection; and literature review.

$\mathrm{AU}$ : Manuscript writing.

\section{REFERENCES}

1. Naimer SA, Trattner A. Transient idiopathic primary penoscrotal edema. Indian J Dermatol 2013; 58:408.

2. Vives F, García-Perdomo HA, Ocampo-Flórez GM. Giant lymphedema of the penis and scrotum: A case report. Autops Case Rep 2016; 6:57-61.

3. Carrasco López C, Torremadé Barreda J, Palacín Porté JA, Franco Miranda E, Viñals Viñals JM. Linfedema scrotal gigante. Cirugía Plástica Ibero-Latinoamericana. Reparadora y Estética 2013; 39:187-91.

4. Sapountzis S, Ciudad P, Lim SY, Chilgar RM, Kiranantawat K, Nicoli $F$, et al. Modified Charles procedure and lymph node flap transfer for advanced lower extremity lymphedema. Microsurgery 2014; 34:439-47.

5. de Godoy JM, Facio FN Jr, de Carvalho EC, Godoy Mde F. New compression mechanism in penile-scrotal lymphedema and sexual rehabilitation. Urol Ann 2014; 6:88-90.

6. Singh V, Sinha RJ, Sankhwar SN, Kumar V. Reconstructive surgery for penoscrotal filarial lymphedema: A decade of experience and follow-up. Urology 2011; 77:1228-31.

7. Thejeswi P, Prabhu S, Augustine AJ, Ram S. Giant scrotal lymphoedema: A case report. Int J Surg Case Rep 2012; 3:269-71.

8. Recalde-Losada C, Rubio-Verdú R, Solesio-Pilarte F, LordaBarraguer E, y Lobato JJ. Abordaje quirúrgico de la elephantiasis escrotal a propósito de dos casos graves. Cir Plást Iberolatinoam 2014; 40:205-12.

9. Heinig B, Wollina U. Complex decongestive therapy. Hautarzt 2015; 66:810-8

10. Torio-Padron N, Stark GB, Földi E, Simunovic F. Treatment of male genital lymphedema: An integrated concept. J Plast Reconstr Aesthet Surg 2015; 68:262-8. 